\title{
PEMBANDINGAN CONTENT MANAGEMENT SYSTEM DENGAN METODE SAW (SIMPLE ADDITIVE WEIGHTING) DALAM IMPLEMENTASI PEMBUATAN WEBSITE SEKOLAH
}

\author{
Gerlan Apriandy Manu ${ }^{1}$, Melli Candra Kande ${ }^{2}$ \\ ${ }^{1,2}$ Pendidikan Informatika, Universitas Citra Bangsa, Prop Nusa Tenggara Timur \\ gerlan.manu@gmail.com ${ }^{1}$, chandra.kande95@gmail.com²
}

\begin{abstract}
ABSTRAK
Salah satu tuntutan era globalisasi dalam dunia pendidikan adalah adanya sebuah pengelolaan sekolah yang terintegrasi dengan sebuah sistem informasi dan teknologi berbasis Komputer. Oleh karena itu, Website merupakan salah satu media penyimpanan informasi dan publikasi yang mudah diakses dari mana saja, kapan saja tanpa terbatas oleh wilayah geografis yang dapat diamanfaatkan oleh sekolah. Content Management System (CMS) adalah perangkat lunak yang memungkinkan seseorang untuk menambahkan atau memanipulasi (mengubah) isi dari suatu situs, Wordpress dan Drupal adalah salah satu CMS yang sering digunakan untuk membuat situs sekolah. Subyek dalam penelitian ini adalah para pengembang situs sekolah menggunakan CMS. Penelitian ini menggunakan Metode Simple Additive Weighting (SAW) untuk membandingkan penggunaan CMS Wordpress dan Drupal dalam membuat situs sekolah. Hasil dari penelitian ini diperoleh pembandingan CMS Drupal dan WordPress dengan nilai terbesar 0,65 untuk Drupal dan 0,52 untuk Wordpress. Sehingga dapat disimpulkan bahwa CMS Drupal lebih efisien dan efektif untuk digunakan sebagai alternatif dalam perancangan Situs Sekolah.
\end{abstract}

Kata Kunci : Content Management System, Simple Additive Weighting, Drupal, Wordpress, Sistem Pendukung Keputusan.

\section{PENDAHULUAN}

Salah satu tuntutan era globalisasi dalam dunia pendidikan adalah adanya sebuah pengelolaan sekolah yang terintegrasi dengan sebuah sistem informasi dan teknologi berbasis Komputer. Oleh karena itu, sudah semestinya sekolah dalam rangka meningkatkan pelayanan dan kualitas pendidikan kepada siswa menggunakan sistem berbasis komputerisasi. Menurut Harianto, Website dapat diartikan sebagai kumpulan halaman yang menampilkan informasi data teks, data gambar data animasi, suara, video atau gabungan dari sejenisnya, baik bersifat statis maupun dinamis yang membentuk suatu rangkaian bangunan yang saling terkait, dimana masing-masing dihubungkan dengan jaringan-jaringan halaman (hyperlink) [2]. Website sekolah sekarang ini menjadi kebutuhan mendasar dari sekolah. Hal ini mendapatkan perhatian dan tanggapan dari berbagai pihak, seperti guru, kepala sekolah, tenaga administrasi sekolah, siswa, osis, dan juga masyarakat. Dengan adanya website sekolah semua pihak bisa merasakan manfaatnya.

Menurut Hidayat, Website atau situs dapat diartikan sebagai kumpulan halamanhalaman yang digunakan untuk menampilkan informasi teks, gambar diam atau gerak, animasi, suara, dan atau gabungan dari semuanya, baik yang bersifat statis maupun dinamis yang menbentuk suatu rangkaian bangunan yang saling 
terkait, yang masing-masing dihubungkan dengan jaringan-jaringan halaman [3]. Menurut Arief, Website adalah salah satu aplikasi yang berisikan dokumen-dokumen multimedia (teks, gambar, suara, animasi, video) di dalamnya yang menggunakan protokol HTTP (Hypertext Transfer Protocol) dan untuk mengaksesnya mengunakan perangkat lunak yang disebut browser. Browser (perambah) adalah aplikasi yang mampu menjalankan dokumen-dokumen web dengan cara diterjemahkan. Prosesnya dilakukan oleh komponen yang terdapat didalam aplikasi browser yang biasa disebut web engine. Semua dokumen web ditampilkan dengan cara diterjemahkan[1].

Content Management System, (CMS) adalah perangkat lunak yang memungkinkan seseorang untuk menambahkan atau manipulasi (mengubah) isi dari suatu situs web. Menurut Rahmadi, umumnya, sebuah CMS terdiri dari dua elemen, yaitu : Aplikasi Manajemen Isi (Content Management Application - CMA) dan Aplikasi Pengiriman Isi (Content Delivery Application, - CDA) [5].

Kemampuan atau fitur dari sebuah CMS berbeda-beda, meski demikian mayoritas CMS ini memiliki fitur publikasi berbasis web, manajemen konten, kontrol revisi, pembuatan index (homepage), pencarian, dan pengarsipan.

Pada penelitian ini, peneliti melakukan pembandingan dua CMS yaitu Wordpress dan Drupal yang sering digunakan oleh pengelola/ develop website untuk membuat situs sekolah. Penelitian ini untuk mengetahui CMS mana yang lebih efektif, efisien dengan metode SAW (Simple Additive Weighting).

Menurut Windarto, Konsep dasar metode SAW adalah mencari penjumlahan terbobot dari rating kinerja pada setiap alternatif pada semua atribut [9].

Penelitian ini mengambil studi kasus pada SMA Kristen Citra Bangsa, yang akan membuat situs sekolah menggunakan CMS. Hasil dari penelitian ini akan memberikan rekomendasi CMS mana yang lebih efektif dan efisien untuk digunakan oleh SMA Kristen Citra Bangsa.

\section{METODE PENELITIAN}

\section{Metode Pembanding}

Penelitian ini menggunakan Metode Simple Additive Weighting (SAW) yaitu suatu metode yang digunakan untuk mencari alternatif yang optimal dari sejumlah alternatif dengan kriteria tertentu. Metode SAW juga sering dikenal dengan istilah metode penjumlahan terbobot.

Menurut Pahlevy, Konsep dasar metode SAW adalah mencari penjumlahan terbobot dari rating kinerja pada setiap alternatif pada semua atribut [4].

Menurut Wibowo, total perubahan nilai yang dihasilkan oleh metode SAW lebih banyak sehingga metode SAW sangat relevan untuk menyelesaikan masalah pengambilan keputusan[8].

\section{Prosedur Penelitian}

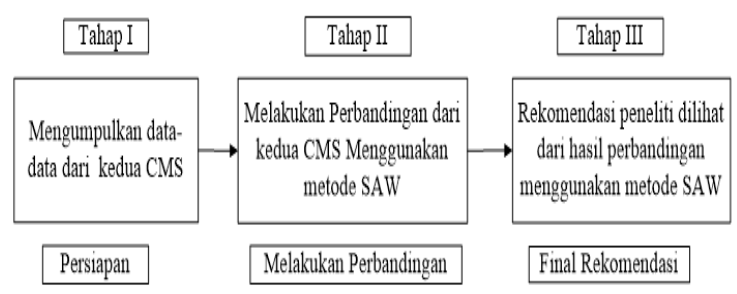

Gambar 1. Prosedur Penelitian

Penelitian ini terdiri dari 3 tahap yaitu : (1) Mengumpulkan data dari kedua CMS. (2) Melakukan perbandingan dari kedua CMS menggunakan Metode SAW. 
Memberikan rekomendasi hasil perbandingan tersebut kepada sekolah.

Berdasarkan langkah pertama, perlu diketahui dan dipahami tentang masingmasing CMS Drupal dan Wordpress. Menurut Waworuntu, Drupal merupakan Web Content Management System berbasis open source yang dirancang untuk dapat menghasilkan website dari skala website sederhana seperti blog pribadi hingga website terdistribusi yang kompleks [6]. Secara umum Drupal memiliki beberapa fitur, yaitu: Node, Comment, Taxonomy, User, Module, Regions \& Blocks, Menus, Theme, dan Views.

Menurut Rahmadi, WordPress adalah sebuah aplikasi sumber terbuka (open source yang sangat popular digunakan sebagai mesin blog atau (blog enginer) [5]. Wordpress memiliki beberapa fitur seperti : Post, Page, Media, Library, Menu, Comment, Appearance - Themes, Widgets, Plugin, Users, Tools, Setting.

Dengan memahami kedua CMS tersebut, peneliti membagikan kuesioner kepada para develop situs atau pengelola situs dengan CMS Drupal dan Wordpress. Kuesionernya berisi tentang kebutuhan mendasar sekolah dalam pembuatan situs sekolah.

Berikut adalah beberapa pertanyaan pada kuesioner untuk para develop situs atau pengelola situs sekolah menggunakan CMS Wordpress.

Apakah CMS WordPress dapat membuat Laman Statik?

Apakah CMS WordPress mudah membuat Laman Statik?

Apakah CMS WordPress dapat Membuat Node? Apakah CMS WordPress dapat Membuat Node?

Apakah CMS WordPress dapat Membuat Taxonomy?

Apakah CMS WordPress dapat Membuat module ? Apakah CMS WordPress mudah membuat module?
Apakah CMS WordPress dapat Membuat Regions \& Blocks

Apakah CMS WordPress mudah Membuat Regions \& Blocks

Apakah CMS WordPress dapat Membuat menus?

Berikut adalah beberapa pertanyaan pada kuesioner untuk para develop situs atau pengelola situs sekolah menggunakan CMS Drupal.

Apakah CMS Drupal dapat membuat Laman Statik? Apakah CMS Drupal mudah membuat Laman Statik?

Apakah CMS Drupal dapat Membuat Node? Apakah CMS Drupal Mudah Membuat Node? Apakah CMS Drupal dapat Membuat Taxonomy? Apakah CMS Drupal dapat Membuat module ? Apakah CMS Drupal mudah membuat module? Apakah CMS Drupal dapat Membuat Regions \& Blocks

Apakah CMS Drupal mudah Membuat Regions \& Blocks

Apakah CMS Drupal dapat Membuat menus?

Bentuk jawaban untuk kedua kuesioner tersebut diatas adalah Ya, Tidak, Tidak Tahu.

Selanjutnya pada tahap kedua, digunakan metode SAW untuk melakukan perbandingan. Jawaban dari kuesioner tersebut diintegrasikan ke dalam pembobotan menggunakan metode SAW dengan rumus :

$$
r i j=\left\{\begin{array}{l}
\frac{X i j}{\max \mathrm{i} X i j} \rightarrow j i k a j \text { adalah atribut keuntungan (benefit) } \\
\frac{\min \mathrm{i} X i j}{X i j} \rightarrow j i k a j \text { adalah atribut keuntungan (cost) }
\end{array}\right.
$$

Dimana:

$$
\begin{aligned}
\mathrm{Rij}= & \text { rating kinerja ternormalisasi dari } \\
& \text { alternatif } \mathrm{Ai}(\mathrm{i}=, 2, \ldots, \mathrm{m})
\end{aligned}
$$

Max i = nilai maksimum dari setiap baris dan kolom. 
Min $\mathrm{i}=$ nilai minimum dari setiap baris dan kolom.

$\mathrm{Xij}=$ baris dan kolom dari matriks.

Formula untuk mencari nilai preferensi untuk setiap alternatif

$$
V i \sum_{j=1}^{n} w j r i j
$$

Dimana:

$\mathrm{Vi}=$ Nilai akhir dari alternatif

$\mathrm{Wi}=$ Bobot yang telah ditentukan

Rij $=$ Normalisasi matriks.

Nilai Vi yang lebih besar mengindikasikan bahwa alternatif Ai lebih terpilih.

Selanjutnya pada tahap ketiga akan terpilih alternatif terbaik dilihat dari penggunaan fitur pada CMS Drupal dan Wordpress dengan nilai alternatif yang terbesar. Dengan ini maka peneliti dapat memberikan rekomendasi pada sekolah untuk menggunakan CMS yang mana yang lebih efektif dan efisien untuk membuat situs sekolah.

\section{HASIL DAN PEMBAHASAN}

\section{Fungsi Fitur-Fitur CMS Wordpress dan Drupal}

Fungsi dari fitur-fitur pada CMS Wordpress dalam pembuatan situs sekolah :

1) Post: Fitur ini merupakan fitur yang sangat penting dan perlu diketahui paling awal. Fitur ini digunakan untuk mengontrol artikel yang di publikasi pada website. Terdapat beberapa menu tambahan yang terdapat pada fitur ini untuk mempermudah dalam pengontrolannya.

2) Media : Fitur ini berfungsi untuk mengontrol media seperti gambar maupun video yang digunakan pada postingan website. Ada beberapa menu tambahan pada fitur ini.

3) Library : Menu ini adalah tempat semua media tersimpan.

4) Pages: Fitur ini digunakan untuk menambahkan pages (halaman). Melalui menu ini pengguna dapat menambahkan deskripsi dari pages yang ditambahkan. Dengan demikian pengunjung akan dimudahkan saat mengunjungi website. Pada fitur ini juga terdapat beberapa fitur tambahan. All Pages: Menu ini menampilkan semua pages (Halaman) yang telah dibuat.

5) Comments: Fitur ini akan menampung semua komentar dari semua artikel pada website.

6) Appearance: Appearance dipakai untuk meletakkan template yang menjadi tampilan website WordPress. Pada fitur ini, pengguna dapat melakukan pengubahan themes atau mengubah template, serta mengunduh berbagai jenis template yang ada di situs resmi http://wordpress.org. Pada fitur ini terdapat beberapa menu tambahan yang aan membantu dalam pengelolaannya.

7) Themes: berfungsi untuk mengatur tema atau template yang digunakan untuk website. Jika ingin mengganti tema website dengan tema yang lain, pengguna bisa menggantinya melalui menu ini.

8) Customize: digunakan untuk mengatur Layout tema yang digunakan pada website.

9) Widgets: Fitur ini biasanya digunakan untuk menambah konten pada bagian 
sidebar maupun footer. Misalnya penambahan popular post ataupun untuk menambahkan iklan

10) Plugin: Fitur ini digunakan untuk mengelola plugin yang ada pada WordPress. Terdapat beberapa menu pendukung untuk membantu pengelolaan fitur ini.

11) Users: memiliki fungsi untuk melihat user website pada WordPress, serta mengatur tingkatan hak akses user untuk login ke dalam website. Dengan menggunakan fitur ini pula, Pengguna dapat mengubah password, serta mengatur keamanan website.

12)Tools: pada saat tertentu, jika pengguna ingin berpindah platform ke website lain. Untuk melakukan export maupun import seluruh isi website

13) Settings: penguasaan fitur ini cukup penting untuk para pemula yang baru menggunakan WordPress. Dengan mengetahui bagian ini dengan baik, dapat mengatur fungsi operasional WordPress.

Berikut adalah fungsi dari fitur-fitur pada CMS Drupal dalam pembuatan situs sekolah :

1) Node : adalah salah satu konten yang terdapat dalam drupal. Sebuah node dapat merupakan blog, topik forum, berita, halaman statis, gambar, video audio maupun flash. Kumpulan node inilah yang membentuk keseluruhan konten dalam sebuah website berbasis Drupal

2) Taxonomy : Node yang begitu banyak perlu dikategorikan sesui topik masing-masing. Di dalam drupal terdapat modul taxonomy yang digunakan untuk mengkategorikan konten.
3) Comment : Komentar atau tanggapan terhadap sebuah node yang dituliskan oleh user

4) Menu : adalah sistem penanganan request melalui $U R L$.

5) Module : Website drupal dapat ditambah dengan modul-modul tertentu sesui keperluan. Modul adalah salah satu program yang ditulis dalam Bahasa Pemrograman PHP yang jika diaktifkan akan menambah fungsi tertentu. Pengelola dapat membuat modul sendiri atau menambahkan modul yang sudah ada dan dapat ditemukan pada laman komunitas drupal.

6) Theme : adalah penampakan luar dari sebuah website drupal. Theme akan mengatur bagaimana website ditampilkan, layout halaman, penempatan blog, style, dan sebagainya. Theme dapat diubah-ubah dengan memilih theme yang tersedia dalam direktori atau menambahkan theme baru yang dapat diunduh pada laman komunitas drupal.

7) Hook adalah metode yang digunakan drupal agar setiap modul dapat menambahkan fungsi tertentu, dengan cara mengaitkan fungsi tertentu tersebut pada hook yang dimiliki sistem drupal.

8) Entity : Entittas digunakan untuk menyimpan dan menampilkan data, yang dapat menjadi node, user, istilah, taksonomi atau pengembangan secara kostum.

9) View : Tidak semua website dengan drupal menggunakan views, namun sebagian besar website dengan drupal menggunakan views untuk melakukan modifikasi terhadap tampilan web. Dengan menggunakan views, pengembang web dapat memilih konten mana saja yang mau 
ditampilkan, bagaimana urutan konten yang di tampilkan, bagaimana menampilkan konten dan lain sebagainya.

10) Regions \& Blocks : Halaman pada website Drupal terbagi-bagi menjadi beberapa regions, antara lain header, footer, sidebars dan content. Regions ditentukan dari theme yang ada. Sedangkan blocks merupakan potongan konten yang ditampilkan pada regions dari halaman web. Blocks dapat berupa konten HTML statis, menu atau navigasi website, hasil output dari module atau konten dinamis yang dibuat oleh pengembang website.

\section{Hasil kuesioner CMS Wordpress dan CMS Drupal dari 10 responden :}

Tabel 1. Hasil Kuesioner CMS Wordpress

\begin{tabular}{|c|l|c|c|c|}
\hline \multirow{2}{*}{ No } & \multicolumn{1}{|c|}{ Pertanyaan } & \multicolumn{3}{|c|}{ Keterangan } \\
\cline { 3 - 5 } & & \multicolumn{1}{|c|}{ Ya } & Tidaks & Tidak tahu \\
\hline 1. & $\begin{array}{l}\text { Apakah CMS WordPress dapat membuat } \\
\text { Laman Statik? }\end{array}$ & 2 & 6 & 2 \\
\hline 2. & $\begin{array}{l}\text { Apakah CMS WordPress mudah } \\
\text { membuat Laman Statik? }\end{array}$ & 1 & 7 & 2 \\
\hline 3. & $\begin{array}{l}\text { Apakah CMS WordPress dapat Membuat } \\
\text { Node ? }\end{array}$ & 8 & 2 & 0 \\
\hline 4. & $\begin{array}{l}\text { Apakah CMS WordPress dapat Membuat } \\
\text { Node ? }\end{array}$ & 9 & 1 & 0 \\
\hline 5. & $\begin{array}{l}\text { Apakah CMS WordPress dapat Membuat } \\
\text { Tcxonomy ? }\end{array}$ & 8 & 3 & 1 \\
\hline 6. & $\begin{array}{l}\text { Apakah CMS WordPress dapat Membuat } \\
\text { module ? }\end{array}$ & 7 & 3 & 0 \\
\hline 7. & $\begin{array}{l}\text { Apakah CMS WordPress mudah } \\
\text { membuat module? }\end{array}$ & 1 & 6 & 3 \\
\hline 8. & $\begin{array}{l}\text { Apakah CMS WordPress dapat Membuat } \\
\text { Regions \& Blocks }\end{array}$ & 1 & 9 & 0 \\
\hline 9. & $\begin{array}{l}\text { Apakah CMS WordPress mudah } \\
\text { Membuat Regions \& Blocks }\end{array}$ & 0 & 5 & 5 \\
\hline 10. & $\begin{array}{l}\text { Apakah CMS WordPress dapat Membuat } \\
\text { menus? }\end{array}$ & 5 & 4 & 1 \\
\hline
\end{tabular}

Tabel 2. Hasil Kuesioner CMS Wordpress

\begin{tabular}{|c|l|c|c|c|}
\hline \multirow{2}{*}{ No } & \multicolumn{1}{|c|}{ Pertanyaan } & \multicolumn{3}{|c|}{ Keterangan } \\
\cline { 3 - 5 } & \multicolumn{1}{|c|}{ Ya } & Tidak & Tidak tahu \\
\hline 1. & $\begin{array}{l}\text { Apakah CMS Drupal dapat membuat } \\
\text { Laman Statik? }\end{array}$ & 10 & 0 & 0 \\
\hline 2. & $\begin{array}{l}\text { Apakah CMS Drupal mudah membuat } \\
\text { Laman Statik? }\end{array}$ & 3 & 7 & 0 \\
\hline 3. & $\begin{array}{l}\text { Apakah CMS Drupal dapat Membuat } \\
\text { Node? }\end{array}$ & 9 & 1 & 0 \\
\hline 4. & $\begin{array}{l}\text { Apakah CMS Drupal Mudah Membuat } \\
\text { Node? }\end{array}$ & 10 & 0 & 0 \\
\hline 5. & $\begin{array}{l}\text { Apakah CMS Drupal dapat Membuat } \\
\text { Taxonomy? }\end{array}$ & 10 & 0 & 0 \\
\hline 6. & $\begin{array}{l}\text { Apakah CMS Drupal dapat Membuat } \\
\text { module ? }\end{array}$ & 10 & 0 & 0 \\
\hline 7. & $\begin{array}{l}\text { Apakah CMS Drupal mudah membuat } \\
\text { module? }\end{array}$ & 6 & 4 & 0 \\
\hline 8. & $\begin{array}{l}\text { Apakah CMS Drupal dapat Membuat } \\
\text { Regions \& Blocks }\end{array}$ & 10 & 0 & 0 \\
\hline 9. & $\begin{array}{l}\text { Apakah CMS Drupal mudah Membuat } \\
\text { Regions \& Blocks }\end{array}$ & 8 & 2 & 0 \\
\hline 10. & $\begin{array}{l}\text { Apakah CMS Drupal dapat Membuat } \\
\text { menus? }\end{array}$ & 10 & 0 & 0 \\
\hline
\end{tabular}

Berdasarkan data pada tabel 1 dan tabel 2 diatas maka diperoleh untuk 10 pertanyaan dan 10 responden pada CMS Wordpress terdapat 47 jawaban Ya, 45 jawaban Tidak dan 17 jawaban Tidak Tahu, sedangkan untuk CMS Drupal terdapat 86 jawaban Ya, 14 jawaban Tidak dan 0 orang Tidak Tahu

\section{Pembobotan}

Terdapat dua Alternatif yaitu A1 dan A2. A1 $=$ Drupal A2 $=$ Wordpress

Berdasarkan hasil kuesioner dihasilkan bobot sebagai berikut : 
Tabel 3. Pembobotan Alternatif A1

\begin{tabular}{|c|c|c|c|}
\hline Altematif A1 Drupal & \multicolumn{3}{|c|}{ Pembobotan } \\
\hline C1a, C1b, C1c & 10 & 0 & 0 \\
\hline C2a, C2b, C2c & 3 & 7 & 0 \\
\hline C3a, C3b, C3c & 9 & 1 & 0 \\
\hline C4a, C4b, C4c & 10 & 0 & 0 \\
\hline C5a, C5b, C5c & 10 & 0 & 0 \\
\hline C6a, C6b, C6c & 10 & 0 & 0 \\
\hline C7a, C7b, C7c & 6 & 4 & 0 \\
\hline C8a, C8b, C8c & 10 & 0 & 0 \\
\hline C9a, C9b, C9c & 8 & 2 & 0 \\
\hline C10a, C10b, C10c & 10 & 0 & 0 \\
\hline
\end{tabular}

Tabel 4. Pembobotan Alternatif A2

\begin{tabular}{|c|c|c|c|}
\hline Alternatif A2 WordPress & \multicolumn{3}{|c|}{ Pembobotan } \\
\hline C1a, C1b, C1c & 2 & 6 & 2 \\
\hline C2a, C2b, C2c & 1 & 8 & 1 \\
\hline C3a, C3b, C3c & 9 & 1 & 0 \\
\hline C4a, C4b, C4c & 9 & 1 & 0 \\
\hline C5a, C5b, C5c & 1 & 8 & 1 \\
\hline C6a, C6b, C6c & 3 & 7 & 0 \\
\hline C7a, C7b, C7c & 1 & 6 & 3 \\
\hline C8a, C8b, C8c & 1 & 9 & 0 \\
\hline C9a, C9b, C9c & 0 & 6 & 4 \\
\hline C10a, C10b, C10c & 5 & 4 & 1 \\
\hline
\end{tabular}

\section{Dimana :}

$\mathrm{C} 1 \mathrm{a}=$ Jumlah yang menjawab pertanyaan $1 \mathrm{Ya}$ $\mathrm{C} 1 \mathrm{~b}=$ Jumlah yang menjawab pertanyaan 1 Tidak $\mathrm{C} 1 \mathrm{c}=$ Jumlah yang menjawab pertanyaan 1 Tidak Tahu

$\mathrm{C} 2 \mathrm{a}=$ jumlah yang menjawab pertanyaan $2 \mathrm{Ya}$

$\mathrm{C} 2 \mathrm{~b}=$ Jumlah yang menjawab Pertanyaan 2 tidak

$\mathrm{C} 2 \mathrm{c}=$ jumlah yang menjawab pertanyaan 2 tidak tahu

$\mathrm{C} 3 \mathrm{a}=$ jumlah yang menjawab pertanyaan 3 ya

$\mathrm{C} 3 \mathrm{~b}=$ Jumlah yang menjawab Pertanyaan 3 tidak

$\mathrm{C} 3 \mathrm{c}=$ jumlah yang menjawab pertanyaan 3 tidak tahu

$\neg \mathrm{C} 4 \mathrm{a}=$ jumlah yang menjawab pertanyaan 4 ya

$\mathrm{C} 4 \mathrm{~b}=$ Jumlah yang menjawab Pertanyaan 4 tidak

$\mathrm{C} 4 \mathrm{c}=$ jumlah yang menjawab pertanyaan 4 tidak tahu

$\mathrm{C} 5 \mathrm{a}=$ jumlah yang menjawab pertanyaan 5 ya

$\mathrm{C} 5 \mathrm{~b}=$ Jumlah yang menjawab Pertanyaan 5 tidak

$\mathrm{C} 5 \mathrm{c}=$ jumlah yang menjawab pertanyaan 5 tidak tahu
C6a $=$ jumlah yang menjawab pertanyaan 6 ya

$\mathrm{C} 6 \mathrm{~b}=$ Jumlah yang menjawab Pertanyaan 6 tidak

C6c $=$ jumlah yang menjawab pertanyaan 6 tidak tahu

$\mathrm{C} 7 \mathrm{a}=$ jumlah yang menjawab pertanyaan 7 ya

$\mathrm{C} 7 \mathrm{~b}=$ Jumlah yang menjawab Pertanyaan 7 tidak

$\mathrm{C} 7 \mathrm{c}=$ jumlah yang menjawab pertanyaan 7 tidak tahu

$\mathrm{C} 8 \mathrm{a}=$ jumlah yang menjawab pertanyaan 8 ya

$\mathrm{C} 8 \mathrm{~b}=$ Jumlah yang menjawab Pertanyaan 8 tidak

$\mathrm{C} 8 \mathrm{c}=$ jumlah yang menjawab pertanyaan 8 tidak tahu

C9a = jumlah yang menjawab pertanyaan 9 ya

$\mathrm{C} 9 \mathrm{~b}=$ Jumlah yang menjawab Pertanyaan 9 tidak

$\mathrm{C} 9 \mathrm{c}=$ jumlah yang menjawab pertanyaan 9 tidak tahu

$\mathrm{C} 10 \mathrm{a}=$ jumlah yang menjawab pertanyaan 10 ya

$\mathrm{C} 10 \mathrm{~b}=$ Jumlah yang menjawab Pertanyaan 10 tidak

$\mathrm{C} 10 \mathrm{c}=$ jumlah yang menjawab pertanyaan 10 tidak tahu

\section{Normalisasi CMS Drupal}

Berdasarkan rumus 1 maka dapat dihitung normasilasi CMS Drupal sebagai berikut :

$$
\begin{aligned}
& \mathrm{r} 11=\frac{10}{\max \{10 ; 3 ; 9 ; 10 ; 10 ; 10 ; 6 ; 10 ; 8 ; 10\}}=\frac{10}{10}=1 \\
& \mathrm{r} 21=\frac{3}{\max \{10 ; 3 ; 9 ; 10 ; 10 ; 10 ; 6 ; 10 ; 8 ; 10\}}=\frac{3}{10}=0,3
\end{aligned}
$$

dan seterusnya maka diperoleh hasil normalisasi sebagai berikut : 


$$
R=\left\{\begin{array}{ccc}
1 & 0 & 0 \\
0.3 & 1 & 0 \\
0.9 & 0.25 & 0 \\
1 & 0 & 0 \\
1 & 0.4 & 0 \\
1 & 0.4 & 0 \\
0.6 & 1 & 0 \\
1 & 0,4 & 0 \\
0.8 & 1 & 0 \\
1 & 0.2 & 0
\end{array}\right\}
$$

Proses perangkingan menggunakan bobot yang telah diberikan oleh pengambil keputusan $\mathbf{w}=\left[\begin{array}{lll}\mathbf{0 , 5 0} & \mathbf{0 , 2 5} & \mathbf{0 , 2 5}\end{array}\right]$

Maka hasil yang diperoleh adalah sebagai berikut :

$$
\begin{aligned}
& \mathrm{V} 1=(0,50)(1)+(0,25)(0)+(0,25)(0)=0,5 \\
& \mathrm{~V} 2=(0,50)(0,3)+(0,25)(1)+(0,25)(0)=0,4 \\
& \mathrm{~V} 3=(0,50)(0,9)+(0,25)(0,25)+(0,25)(0)=0,51 \\
& \mathrm{~V} 4=(0,50)(1)+(0,25)(0,4)+(0,25)(0)=0,6 \\
& \text { V5 }=(0,50)(1)+(0,25)(0,4)+(0,25)(0)=0,6 \\
& \text { V6 }=(0,50)(0,6)+(0,25)(1)+(0,25)(0)=0,55 \\
& \text { V7 }=(0,50)(1)+(0,25)(0,4)+(0,25)(0)=0,6 \\
& \text { V8 }=(0,50)(1)+(0,25)(0,4)+(0,25)(0)=0,6 \\
& \text { V9 }=(0,50)(0,8)+(0,25)(1)+(0,25)(0)=0,65 \\
& \text { V10 }=(0,50)(1)+(0,25)(0,2)+(0,25)(0)=0,55
\end{aligned}
$$

Berdasarkan hasil normalisasi dari A1 di atas, nilai terbesar ada pada V9 yang berjumlah 0,65 dan terpilih sebagai alternatif terbaik pada CMS Drupal, artinya dari 10 responden yang memilih CMS Drupal dilihat dari kelebihan fungsinya yaitu pada Region \& Blok.

\section{Normalisasi CMS Wordpress}

Berdasarkan rumus 1 maka dapat dihitung normasilasi CMS Drupal sebagai berikut :

$$
\begin{aligned}
& \mathrm{r} 11=\frac{2}{\max \{2 ; 1 ; 9 ; 9 ; 1 ; 3 ; 1 ; 1 ; 0 ; 5\}}=\frac{2}{9}=0,2 \\
& \mathrm{r} 21=\frac{1}{\max \{1 ; 9 ; 9 ; 1 ; 3 ; 1 ; 1 ; 0 ; 5\}}=\frac{1}{9}=0,1
\end{aligned}
$$

dan seterusnya maka diperoleh hasil normalisasi sebagai berikut :

$$
R=\left\{\begin{array}{ccc}
0.2 & 0.6 & 0.88 \\
0.1 & 0.88 & 0.25 \\
0.1 & 0.11 & 0 \\
1 & 0.1 & 00 \\
0.2 & 0.88 & 0.25 \\
0.6 & 0.78 & 0 \\
0 & 0.2 & 0.33 \\
0.2 & 0.66 & 0.25 \\
0 & 1 & 1 \\
0 & 1 & 1
\end{array}\right\}
$$

Proses perangkingan menggunakan bobot yang telah diberikan oleh pengambil keputusan $\mathbf{w}=[\mathbf{0 , 5 0} 0,250,25]$

Maka hasil yang diperoleh adalah sebagai berikut :

$$
\begin{aligned}
& \mathrm{V} 1=(0,50)(0,2)+(0,25)(0,66)+(0,25)(0,8)=0,46 \\
& \mathrm{~V} 2=(0,50)(0,1)+(0,25)(0,88)+(0,25)(0,25)=0,33 \\
& \mathrm{~V} 3=(0,50)(1)+(0,25)(0,11)+(0,25)(0)=0,52 \\
& \mathrm{~V} 4=(0,50)(1)+(0,25)(0,11)+(0,25)(0)=0,52 \\
& \text { V5 }=(0,50)(0,2)+(0,25)(0,88)+(0,25)(0,25)=0,32 \\
& \text { V6 }=(0,50)(0,6)+(0,25)(0,78)+(0,25)(0)=0,49 \\
& \text { V7 }=(0,50)(0)+(0,25)(0,2)+(0,25)(0,33)=0,13 \\
& \text { V8 }=(0,50)(0,2)+(0,25)(0,66)+(0,25)(0,25)=0,32
\end{aligned}
$$




$$
\begin{aligned}
& \mathrm{V} 9=(0,50)(0)+(0,25)(1)+(0,25)(1)=0,5 \\
& \mathrm{~V} 10=(0,50)(0)+(0,25)(1)+(0,25)(1)=0,5
\end{aligned}
$$

Berdasarkan hasil normalisasi dari A2 di atas dapat disimpulkan bahwa Nilai terbesar ada pada V3 dan V4 yang berjumlah 0,52 dan terpilih sebagai alternatif terbaik pada CMS WordPress. Artinya dari 10 responden yang memilih CMS WordPress dilihat dari kelebihan fungsinya yaitu pada Pembuatan Postingan (Node/Post).

\section{KESIMPULAN}

Terhadap dua jenis Content Management System (CMS) yaitu Drupal dan WordPress dengan nilai terbesar 0,65 untuk Drupal dan 0,52 untuk Wordpress, dapat disimpulkan bahwa CMS Drupal lebih efektif dan efisien untuk digunakan sebagai alternatif dalam Perancangan Situs Sekolah dengan keunggulannya yaitu pada fitur Region \& Block.

\section{DAFTAR PUSTAKA}

[1] Arief. 2011 Pembuatan Website Sekolah Menengah Pertama Negeri 3 Delanggu dengan Menggunakan Php dan MySQL

[2] Harianto. 2015. Membuat Web Profil Sekolah + PPDB Online. Yogyakarta: Lokomedia

[3] Hidayat. 2010. Cara Praktis Membangun Website Gratis. Jakarta: Komputindo

[4] Pahlevy. 2010. Implementation Of Simple Additive Weighting (Saw) Methode In Determining High School Student's Interest. Semarang: 50196
[5] Rahmadi. 2013. Tips Membuat Website Tanpa Coding dan Langsung Online. Yogyakarta: ANDI

[6] Waworuntu, Tanuar. 2013. Document Management System Menggunakan Open-Source CMS Drupal

[8] Wibowo S 2010. Implementasi Metode Simple Additive Weighting (SAW) dalam sistem informasi lowongan kerja berbasis web untuk rekomendasi pencari kerja terbaik

[9] Windarto. 2010. Implementasi Metode Topsis dan SAW Dalam Memberikan Reward Pelanggan. 2406-7857 